\title{
AN INTEGRATED APPROACH FOR PRIORITIZING PROJECTS FOR IMPLEMENTATION USING AHP
}

\author{
Christian Tabi Amponsah \\ Faculty of Business and Management \\ University Canada West \\ Vancouver, BC, Canada \\ Email: chris_tabi@hotmail.com
}

\begin{abstract}
This paper presents the Analytic Hierarchy Process (AHP) as a potential decision making method for prioritizing road projects for implementation. An examination of the way implementing agencies decide over which road project to select for execution reviews a constant desire to have a clear, objective and scientific criteria. However, decision making is, in its totality, a cognitive and mental process derived from the most possible adequate selection based on tangible and intangible criteria, which are arbitrarily chosen by those who make the decisions. In this paper, a hierarchical structure is constructed with data from a regional road directorate's scheduled potential roads for implementation based on commonly known factors used by agencies for selecting projects. An integrated factor base (IFB) taking into consideration, the Social, Legal, Environments, Economic, Political and Technological (SLEEPT) influence of roads has been developed to aid in providing a systematic approach for prioritizing road projects. By applying the AHP, candidate projects can be prioritized in descending-order of the most viable project to be selected for implementation. The paper shows the adequacy of the AHP and proposes the use of simplified professional software, the 'Expert Choice' that is available commercially and designed for implementing AHP. It is hoped that this will encourage the application of the AHP by project officials and other project management professionals for implementing projects.
\end{abstract}

Keywords: Analytical hierarchy process; integrated factor base, project management; project selection

\section{$1 \quad$ Introductory Background}

Road transport infrastructure is a crucial driver of development, bringing socio-economic opportunities within the reach of the poor and enabling economies to be competitive and thrive in a globalized world (The World Bank, 2008). Road transportation is seen as the backbone of economic development and connects people to the services they need by allowing people to interact and generate the knowledge that creates long-term growth. A successful organization recognizes that when an effective strategy is properly implemented, it will result in a sustainable competitive advantage. Examining the formulation of an organizational strategy, it becomes evident that strategy is really about choices. In this context, choices mean making the correct decisions, selecting the best alternatives and periodically optimizing the choices as the organizational environment changes (Kendrick \& Saaty, 2007).

An examination of the way implementing agencies decide over which road project to select for execution reviews a constant desire to have a clear, objective and scientific criteria (Haas \& Meixner, 2005). However, decision making is, in its totality, a cognitive and mental process derived from the most 
possible adequate selection based on tangible and intangible criteria (Saaty, 2007), which are arbitrarily chosen by those who make the decisions.

During the process of evaluating individual projects or groups of projects and choosing to implement a set of them to meet the objectives of organizations, the selection team ensures that several conditions are met. These conditions may vary widely from firm to firm but may involve the assessment of the project potential profitability, chance of meeting return-on-investment, meeting the requirements of the law or rules of industrial association, the availability of skills and knowledge for implementing the project, meeting project deadline and the possibility of meeting all technical and economic feasibilities (Mantel, Meredith, Shafer \& Sutton, 2011). Consequently, differing methods are employed but can generally be categorized into numeric and non-numeric.

There is a general understanding that the conventional transport planning approaches, based on transport user cost savings, cannot easily work for all types of road investments, particularly when modal change is forecast, social pressures are induced or there is a high chance of road closure (Odoki, Ahmed, Taylor \& Okello, 2008). For example, the current engineering and economic models cannot adequately capture the benefits to deprived communities if improving infrastructures that lead to better schooling, better health care, or the provision of other services such as piped water supply, the provision of electricity, a newly established market or better emergency food distribution. Sometime socio-political issues which are at the heart of the electorate are not easy to justify within the conventional criteria for selecting projects for development.

Past attempts to overcome these problems have lacked consistency (Ghasemzadeh \& Archer, 2000). Therefore, there is a need to develop an integrated framework to address the poverty, political and social benefit aspects in a systematic manner. In a study conducted on the topic "identification and treatment of social benefits in road transport project appraisal" in 2005, Eugene and Dey, highlighted the problems of identification, separation, measurement, forecasting and valuation of social benefits within a cost-benefit approach framework. It recommended a flexible approach using the principles of multi-criteria analysis (MCA) that is capable of combining qualitative and quantitative data into a single analytical framework. One of the study outputs was a computerized software tool that can be used alone or within the framework of globally accepted appraisal models. Although such tools appear to be robust in methodological terms, there are fundamental operational problems, including the choice of the benefit/cost indicators and their weights. The current study outlines a procedure that incorporates into the most popular models the aspect of socio-political issues.

In this paper, a hierarchical structure is constructed using proposed road projects from a regional highway office as an example based on commonly known factors used by highway implementing agencies for selecting projects. An integrated factor base (IFB) taking into consideration, the Social, Legal, Environmental, Economic, Political and Technological (SLEEPT) profile of roads has been developed to aid in providing a systematic approach for prioritizing road projects. By applying the AHP, candidate projects can be prioritized and in a descending-order list of projects that can be made in order to select the most viable project for implementation. The sensitivity analysis can be performed to check the sensitivity of the final decisions, if required.

\section{Traditional methods of prioritizing road projects for implementation}

Organizations identify many potential projects as part of their strategic planning processes, but the list of potential projects needs to be narrowed down to those that will be most beneficial. Selecting projects is not an exact science, but it is a critical part of project management. Many methods exist for selecting from among possible projects. Four common techniques are: Focusing on broad organizational needs; 
Categorizing information technology projects; Performing net present value or other financial analyses and Using a weighted scoring model.

There are numerous tools that are used qualitatively and quantitatively to achieve the objectives listed above. Among the Qualitative Models are;

- Subject Matter Expert (SME) judgments (based on SME's knowledge + expertise)

- "Sacred Cow" (pressure from upper management -politicians who wants project done in their way)

- Mandates (generated from external vendors such as funding agencies and institutions)

The Quantitative Models are based on financial considerations that can be calculated on the philosophy of "time value of money" and that all things being equal, it is better to have money now rather than later. The major underpinning being that $\$ n$ today is "worth" more than $\$ n$ one year from today due to inflation and risk. Of these, the cost of money is the most predictable, hence, it is the essential component of economic analysis. Cost of money is represented by (1) money paid for the use of borrowed money, or (2) return on investment. Cost of money is determined by an interest rate. Time value of money is defined as the time-dependent value of money stemming both from changes in the purchasing power of money (inflation or deflation) and from the real earning potential of alternative investments over time (Mehrez \& Sinuany-Stern, 1983). The economic and financial analysis of the project is based on the comparison of the cash flow of all costs and benefits resulting from the project's activities. There are four common methods of comparing alternative investments:

- Net present value,

- Rate of Return,

- Benefit-Cost analysis, and

- Pay Back Period.

Each of these is dependent on a selected interest rate or discount rate to adjust cash flows at different points in time (Lockett \& Stratford, 1987).

Central part of the project selection process is evaluation and prioritization of identified projects. Although decisions are based on values and preferences of the decision makers, a set of criteria or specific objectives can be used while prioritizing projects and determining the real meaning of an optimal relationship between benefits and costs.

There are a couple of methods available, and the main criteria groups are, Financial, Strategic, Risks (Threats), Technical Knowledge and Stakeholder commitment. These methods require a certain minimum level of "planning" for each one of the projects to be evaluated. For example, we need to know, project life cycle duration, in number of accounting periods, expected project cost per accounting period, expected project revenue per accounting period, overall risk values of the projects to be evaluated.

Usually, we do this whole evaluation in definition or early planning phase and then have estimates of those values and make sure that the estimation accuracies are comparable. Although such models have a sound empirical base, model users should be aware of the limitations enshrine in them. For example, models do not endogenously predict road accidents or their costs, nor environmental impacts such as air and noise pollution, nor traffic delay costs during road construction or maintenance. Facility is provided, however, to incorporate accident costs, delays, and environmental impacts where exogenous estimates are available. The social, legal, political interferences can be enormous. Hence, to provide adequate judgment for their selection, there are certain minimum levels of "planning" for each project to be evaluated.

\subsection{The Highway Development Management Model (HDM-4)}


One of the well known models for appraising road projects is the Highway Development and Management Model (HDM-4) which seeks to address road investment related social issues. The HDM-4 has the ability to rank investment alternatives based on the perceived importance of a range of criteria, one of which is labeled 'Social Benefits and Costs'. However, there are some limitations to the current methodology used for the inclusion of Social Benefits within the HDM-4 MCA framework:

- The Social Benefits/Costs cannot be further broken down into a hierarchy reflecting levels of detail at which the different types of benefits and costs can be identified;

- The indices that can be defined for the performance of each alternative in meeting the study objective of maximizing or optimizing social benefits are very broad;

- Issues relating to political pressures from the electorates that drive the selection of projects are not normally captured.

The analytic hierarchy process (AHP) method has proven to be extremely valuable in business process improvement, prioritization decisions when they involve both tangible and intangible strategic considerations.

\section{The Analytic Hierarchy Process (AHP)}

The Analytic Hierarchy Process (AHP) is a decision-aiding method developed by Saaty $(1980,1985$ \& 1990). It aims at quantifying relative priorities for a given set of alternatives on a ratio scale, based on the judgment of the decision-maker, and stresses the importance of the intuitive judgments of a decisionmaker as well as the consistency of the comparison of alternatives in the decision-making process (Saaty, 1980). Since a decision-maker bases judgments on knowledge and experience, then makes decisions accordingly, the AHP approach agrees well with the behavior of a decision-maker. The strength of this approach is that it organizes tangible and intangible factors in a systematic way, and provides a structured yet relatively simple solution to the decision-making problems (Skibniewski \& Chao 1992). In addition, by breaking a problem down in a logical fashion from the large, descending in gradual steps, to the smaller and smaller, one is able to connect, through simple paired comparison judgments, the small to the large.

Kendrick \& Saaty (2007), outlines six advantages to using AHP over other alternative project selection and prioritization techniques:

1. Because AHP uses a hierarchical structure, it enables decision makers to define high level strategic objectives and specific metrics for a better assessment of strategic alignment.

2. AHP goes beyond financial analysis by integrating quantitative and qualitative considerations as well as competing stakeholder inputs into setting priorities.

3. AHP enables decision makers to measure the relative importance of projects, including their benefits, costs, risks and opportunities so resources can be allocated to get the best 'bang for the buck' .

4. AHP can be applied in any organization with any level of maturity because the inputs are normalized using either numerical data or subjective judgments when metrics are not available.

5. The AHP process lends itself to sensitivity analysis, providing practitioners with greater analytical capabilities when examining what-if scenarios.

6. The auditable and explicit structure of the decision model creates a strong framework for systematically improving project selection and allocation decisions. 
Table 1: Project example for 5 projects and SLEEPT factor and sub-factors

\begin{tabular}{|c|c|c|c|c|c|c|}
\hline \multirow{2}{*}{\multicolumn{2}{|c|}{ Project }} & \multirow[b]{2}{*}{$\begin{array}{c}\text { Project } \\
\text { A }\end{array}$} & \multirow[b]{2}{*}{$\begin{array}{c}\text { Project } \\
\text { B }\end{array}$} & \multirow[b]{2}{*}{$\begin{array}{l}\text { Project } \\
\text { C }\end{array}$} & \multirow[b]{2}{*}{$\begin{array}{l}\text { Project } \\
\text { D }\end{array}$} & \multirow[b]{2}{*}{$\begin{array}{c}\text { Project } \\
\text { E }\end{array}$} \\
\hline & & & & & & \\
\hline \multirow{9}{*}{ Social } & Increased access to health facilities & 7 & 7 & 5.5 & 7.5 & 7.0 \\
\hline & Increased access to clean water sources & 6.5 & 5.5 & 5.5 & 6.0 & 7 \\
\hline & $\begin{array}{llll}\begin{array}{l}\text { Increased } \\
\text { institutions }\end{array} & \text { access } & \text { to } & \text { educational } \\
\end{array}$ & 6 & 7 & 6 & 7 & 7 \\
\hline & Access to information, new knowledge, & 7 & 7 & 8 & 6 & 5.5 \\
\hline & Modernity & 6 & 5 & 5.5 & 6.5 & 6.5 \\
\hline & Increased road accidents & 7 & 7 & 7 & 5.5 & 5.5 \\
\hline & Increased insecurity \& crime & 5 & 6 & 6 & 7 & 7 \\
\hline & Increased incidences of diseases & 4.5 & 5.5 & 5.5 & 8 & 6.5 \\
\hline & Negative cultural influence & 6 & 7 & 5 & 6 & 7 \\
\hline \multirow{3}{*}{ Legal } & Loss of land/property acquisition & 4.6 & 6 & 7 & 7.5 & 5.5 \\
\hline & Compensation payment & 7 & 7.5 & 6 & 6 & 7 \\
\hline & Loss of land/property acquisition & 7 & 7 & 7.5 & 8 & 6 \\
\hline \multirow{5}{*}{ Environmental } & Dust & 7 & 7 & 7 & 7 & 7 \\
\hline & Pollution & 8.5 & 7 & 6.5 & 7.5 & 5.5 \\
\hline & Social consequences on environment & 7.5 & 6 & 7.5 & 7 & 7.7 \\
\hline & Land degradation & 7 & 7.5 & 8 & 6.5 & 7 \\
\hline & Settlement/resettlement & 7 & 6.5 & 7 & 8 & 7.5 \\
\hline \multirow{5}{*}{ Economical } & Net Present Value (NPV) & 8 & 7 & 7 & 6.5 & 6.5 \\
\hline & Economic Rate of Return (ERR) & 7 & 6.5 & 7.5 & 7 & 6.5 \\
\hline & Benefit Cost Ratio (BCR), NPV/C & 7 & 7 & 87.5 & 8 & 6.5 \\
\hline & First Year Rate of Return (FYRR) & 7.5 & 7.5 & 7.5 & 7 & 8.5 \\
\hline & Construction Cost $(\$)$ & 16.8 & 18 & 17.5 & 18.4 & 17.0 \\
\hline \multirow{4}{*}{ Political } & Fairness in providing road access & 7 & 6.5 & 7 & 8 & 7 \\
\hline & Promotion of political stability & 6.5 & 7 & 7 & 6.5 & 7.5 \\
\hline & Strategic importance of roads, etc. & High & High & Medium & High & Medium \\
\hline & $\begin{array}{l}\text { A representative value is externally } \\
\text { defined by the user for each alternative }\end{array}$ & 8 & 7.5 & 6.5 & 7 & 6.5 \\
\hline \multirow{7}{*}{ Technological } & Maximize energy & 7 & 7 & 8 & 6.5 & 6.5 \\
\hline & Efficiency $(\%)$ & 90 & 75 & 75 & 80 & 88 \\
\hline & Functional & 6.5 & 7.5 & 7 & 6.5 & 6.5 \\
\hline & Service level & 7 & 8 & 7 & 8 & 8 \\
\hline & Safety & 9 & 9 & 9 & 9 & 9 \\
\hline & Annual Average Daily (AADT) Traffic - & 3,000 & 3,300 & 3,200 & 3,050 & 3,100 \\
\hline & Length $(\mathrm{km})$ & 34.5 & 40.5 & 38.5 & 42.5 & 36 \\
\hline
\end{tabular}

\section{Road Project Prioritizing Case Example}


Data from a regional roads directorate administering road project in an emerging economy has been chosen to demonstrate the effectiveness of the AHP model for selecting the most viable road for implementation. The road corridors under consideration have been dubbed A to $\mathrm{F}$. These projects have been planned for execution under funding arrangements.

To simplify calculations, the factors that will be used in the project example are Social, Legal, Environmental, Economical, Political and technological (SLEEPT). Other criteria can be added if necessary, together with a suggestion that a computer should be used to simplify calculations. The main factors necessary for evaluating a project are summarized in Table 1 above.

By following the AHP outline indicated above, the hierarchy of the problem can be developed as shown in Figure 1 below. For steps 3, the decision-makers have to indicate preferences or priorities for each decision alternative in terms of how it contributes to each criterion as shown in Table 2.

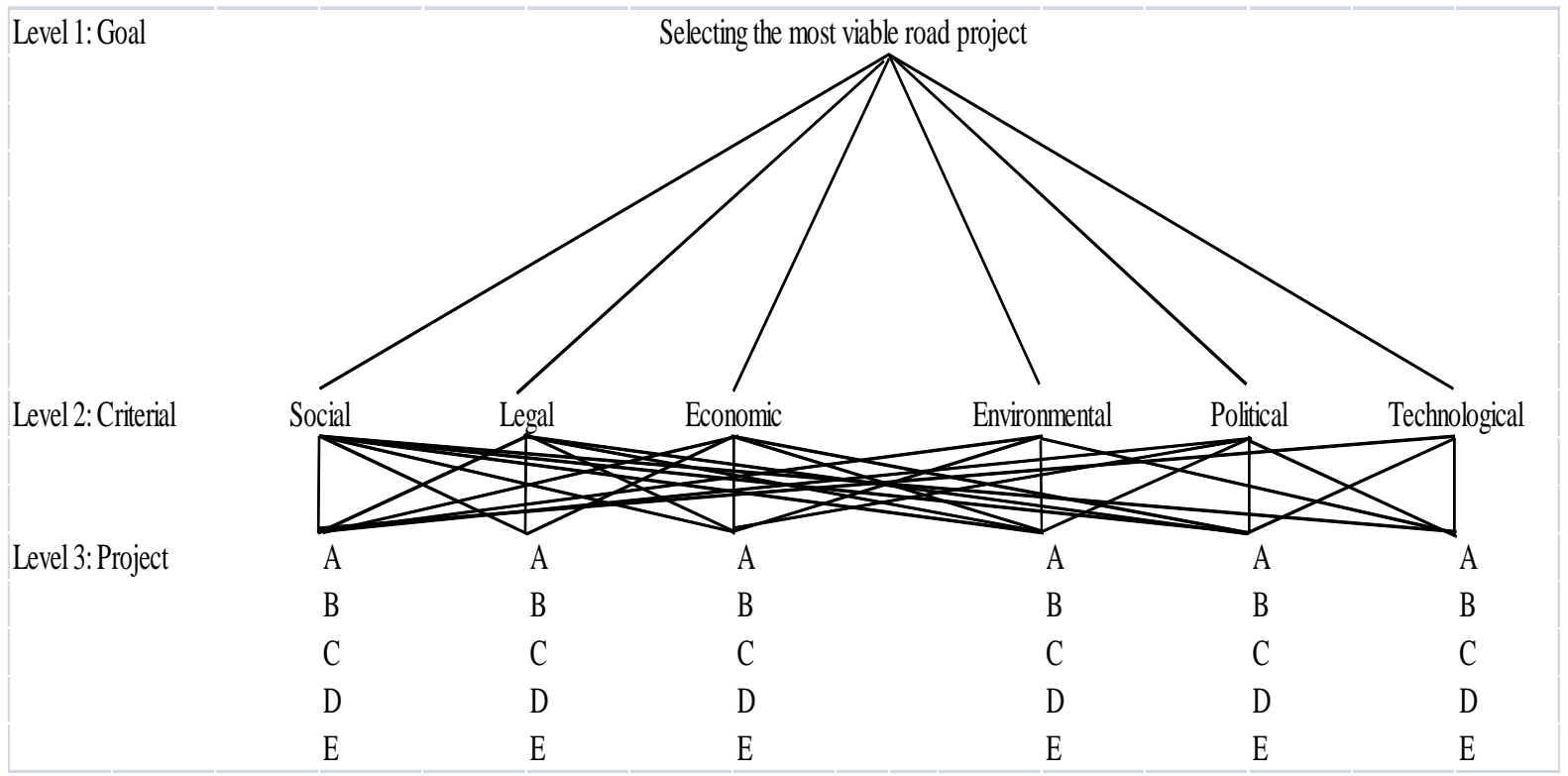

Figure 1: Hierarchy of road project example A,B,C,D and E are candidate roads under consideration

The following can be done manually of automatically by using the Expert Choice software.

1. Synthesizing the pair-wise comparison matrix

2. Calculating the priority vector for a criterion such as technological

3. Calculating the consistency ratio

4. Calculating $\lambda_{\max }$

5. Selecting appropriate value of the random consistency ratio from Table 4

6. Checking the consistency of the pair-wise comparison matrix to check whether the decisionmakers' comparison were consistent or not.

For illustration purposes the calculation for these items are made. Synthesizing the pair-wise comparison matrix performed by dividing each element of the matrix by its column total. 
For example, the value 0.087 in Table 3 is obtained by dividing 1 from Table 2 by 11.5 , which is the sum of values in Table $2 ;(1+2+5+3+1 / 2)$.

The priority vector in Table 3 can be obtained by finding the row averages. For example, the priority of project A with respect to the criterion "Social" in Table 3 is calculated by dividing the sum of the rows $(0.087+0.071+0.040+0.133+0.200)$ by the number of projects i.e. 5 in order to obtain the value 0.106 . The priority vector for Social factor, indicated in Table 3 is given below:

Table 2. Pair-wise comparison matrix for Social

\begin{tabular}{llllll}
\hline Social & A & B & C & D & E \\
\hline A & 1 & $1 / 2$ & $1 / 5$ & $1 / 3$ & 2 \\
B & 2 & 1 & $1 / 2$ & $1 / 3$ & 2 \\
C & 5 & 2 & 1 & $1 / 3$ & 3 \\
D & 3 & 3 & 3 & 1 & 2 \\
E & $1 / 2$ & $1 / 2$ & $1 / 3$ & $1 / 2$ & 1 \\
\hline & 11.5 & 7.0 & 5.0 & 2.5 & 10 \\
\hline
\end{tabular}

Table 3. Synthesized matrix for Social Factor

\begin{tabular}{lllllll}
\hline Social & A & B & C & D & E & $\begin{array}{l}\text { Priority } \\
\text { Vector }\end{array}$ \\
\hline A & 0.087 & 0.071 & 0.040 & 0.133 & 0.200 & 0.106 \\
B & 0.174 & 0.143 & 0.099 & 0.133 & 0.200 & 0.150 \\
C & 0.435 & 0.286 & 0.199 & 0.133 & 0.300 & 0.271 \\
D & 0.261 & 0.429 & 0.596 & 0.400 & 0.200 & 0.377 \\
E & 0.043 & 0.071 & 0.066 & 0.200 & 0.200 & 0.096 \\
\hline \multicolumn{1}{c}{$\sum=1.000$} \\
\hline$\lambda_{\max }=5.4367 ;$ CI $=0.1093 ;$ RI $=1.12 ; C R=0.0976<.1$ & OK
\end{tabular}

Now, estimating the consistency ration is as follows:

$$
0.106\left[\begin{array}{c}
1.00 \\
2.00 \\
5.000 \\
3.00 \\
0.50
\end{array}\right]+0.150\left[\begin{array}{l}
0.50 \\
1.00 \\
2.00 \\
3.00 \\
0.50
\end{array}\right]+0.271\left[\begin{array}{l}
0.20 \\
0.50 \\
1.00 \\
3.00 \\
0.33
\end{array}\right]+0.377\left[\begin{array}{l}
0.33 \\
0.33 \\
0.33 \\
1.00 \\
0.50
\end{array}\right]+0.096\left[\begin{array}{l}
2.00 \\
2.00 \\
3.00 \\
2.00 \\
1.00
\end{array}\right]=\left[\begin{array}{l}
0.55 \\
0.82 \\
1.52 \\
2.15 \\
0.50
\end{array}\right]
$$

Dividing all elements of the weighted sum matrices by their respective priority vector elements we obtain:

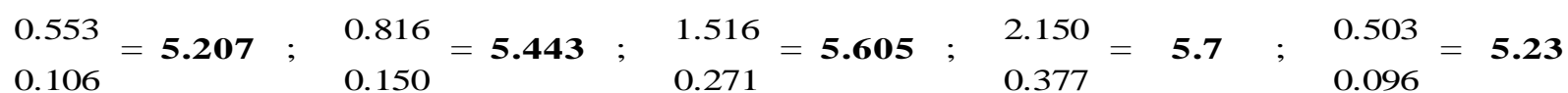

We the compute the average of these values to obtain $\lambda_{\max }$

$$
\begin{aligned}
\lambda_{\max } & =\frac{(5.2073+5.4432+5.6048+5.7004+5.228)}{5} \\
& =5.4367
\end{aligned}
$$

Now, we find the consistency index. CI as follows

$$
\mathrm{CI}=\frac{\lambda_{\max -}}{n-1}=\frac{5.4373-5}{5-1}=\frac{0.4373}{4}=0.1093
$$

Selecting appropriate value of the random consistency ration, RI for the matrix size of five using table 2, we find $\mathrm{RI}=1.12$. We then calculate the consistency ration, $\mathrm{CR}$ as follows:

$\mathrm{CR}=\mathrm{CI} / \mathrm{RI}=0.1093 / 1.12=\underline{\mathbf{0 . 0 9 7 6}}$ 
Judgment consistency can be checked by taking the consistency ratio (CR) of CI with the appropriate value as shown in Table 4 below. The CR is acceptable if it does not exceed 0.10 . If it exceeds the judgment matrix is inconsistent and will require review and improvement.

Table 4. Random Consistency Values

\begin{tabular}{|l|c|c|c|c|c|c|c|c|c|}
\hline Size of Matrix & 1 & 2 & 3 & 4 & 5 & 6 & 7 & 8 & 9 \\
\hline $\begin{array}{l}\text { Random } \\
\text { Consistency }\end{array}$ & 0 & 0 & 0.58 & 0.9 & 1.12 & 1.24 & 1.32 & 1.41 & 1.45 \\
\hline
\end{tabular}

Random consistency with corresponding matrix size, (Saaty, 1980, 1985, 1990)

As the value of CR is less than 0.1 , the judgments are acceptable.

Similarly, the pair-wise comparison matrices and priority vectors for the remaining criteria can be found as shown in tables $5-9$ respectively.

Table 5. Pair-wise comparison matrix for Legal

\begin{tabular}{lllllll}
\hline Legal. & $\mathrm{A}$ & $\mathrm{B}$ & $\mathrm{C}$ & $\mathrm{D}$ & $\mathrm{E}$ & $\begin{array}{l}\text { Priority } \\
\text { Vector }\end{array}$ \\
\hline $\mathrm{A}$ & 1 & 6 & 6 & 2 & 6 & 0.476 \\
$\mathrm{~B}$ & $1 / 6$ & 1 & $1 / 3$ & $1 / 2$ & 3 & 0.092 \\
$\mathrm{C}$ & $1 / 6$ & 3 & 1 & $1 / 2$ & 5 & 0.158 \\
$\mathrm{D}$ & $1 / 2$ & 2 & 2 & 1 & 6 & 0.230 \\
$\mathrm{E}$ & $1 / 6$ & $1 / 3$ & $1 / 5$ & $1 / 6$ & 1 & 0.044 \\
\hline
\end{tabular}

Table 6. Pair-wise comparison matrix for Econ.

Table 7. Pair-wise comparison matrix for Environ

\begin{tabular}{lllllll}
\hline Economic & $\mathrm{A}$ & $\mathrm{B}$ & $\mathrm{C}$ & $\mathrm{D}$ & $\mathrm{E}$ & $\begin{array}{l}\text { Priority } \\
\text { Vector }\end{array}$ \\
\hline $\mathrm{A}$ & 1 & $1 / 2$ & $1 / 4$ & 2 & 3 & 0.147 \\
$\mathrm{~B}$ & 2 & 1 & $1 / 3$ & 5 & 2 & 0.225 \\
$\mathrm{C}$ & 4 & 3 & 1 & 6 & 4 & 0.467 \\
$\mathrm{D}$ & $1 / 2$ & $1 / 5$ & $1 / 6$ & 1 & 2 & 0.084 \\
$\mathrm{E}$ & $1 / 3$ & $1 / 2$ & $1 / 4$ & $1 / 2$ & 1 & 0.076 \\
\hline
\end{tabular}

Table 8. Pair-wise comparison matrix for Political

\begin{tabular}{lllllll}
\hline Environ. & A & B & C & D & E & $\begin{array}{l}\text { Priority } \\
\text { Vector }\end{array}$ \\
\hline $\mathrm{A}$ & 1 & $1 / 7$ & $1 / 8$ & 2 & 3 & 0.085 \\
$\mathrm{~B}$ & 7 & 1 & $1 / 3$ & 6 & 5 & 0.282 \\
$\mathrm{C}$ & 8 & 3 & 1 & 9 & 9 & 0.534 \\
$\mathrm{D}$ & $1 / 2$ & $1 / 6$ & $1 / 9$ & 1 & 2 & 0.057 \\
$\mathrm{E}$ & $1 / 3$ & $1 / 5$ & $1 / 9$ & $1 / 2$ & 1 & 0.041 \\
\hline
\end{tabular}

\begin{tabular}{lllllll}
\hline Political & A & B & C & D & E & $\begin{array}{l}\text { Priority } \\
\text { Vector }\end{array}$ \\
\hline $\mathrm{A}$ & 1 & $1 / 2$ & $1 / 3$ & 3 & 3 & 0.144 \\
$\mathrm{~B}$ & 5 & 1 & 5 & 6 & 6 & 0.537 \\
$\mathrm{C}$ & 3 & $1 / 5$ & 1 & 2 & 2 & 0.173 \\
$\mathrm{D}$ & $1 / 3$ & $1 / 6$ & $1 / 2$ & 1 & 2 & 0.084 \\
$\mathrm{E}$ & $1 / 3$ & $1 / 6$ & $1 / 2$ & $1 / 2$ & 1 & 0.062 \\
\hline
\end{tabular}

Table 9. Pair-wise comparison matrix for Technology.

\begin{tabular}{lllllll}
\hline & A & B & C & D & E & $\begin{array}{l}\text { Priority } \\
\text { Vector }\end{array}$ \\
\hline $\mathrm{A}$ & 1 & 6 & 1 & 2 & 8 & 0.298 \\
$\mathrm{~B}$ & $1 / 7$ & 1 & $1 / 4$ & $1 / 3$ & 2 & 0.071 \\
$\mathrm{C}$ & 2 & 4 & 1 & 4 & 9 & 0.431 \\
$\mathrm{D}$ & $1 / 2$ & 3 & $1 / 4$ & 1 & 6 & 0.164 \\
$\mathrm{E}$ & $1 / 8$ & $1 / 2$ & $1 / 9$ & $1 / 7$ & 1 & 0.036 \\
\hline
\end{tabular}

In addition to the pair-wise comparison for the decision alternatives we also use same pair-wise comparison procedure to set priorities for all six criteria in terms of importance of each in contributing to 
the overall goal. Table 10 shows the pair-wise comparison matrix and priority vector for the next six criteria.

Table 10. Pair-wise comparison matrix for the six criteria

\begin{tabular}{|c|c|c|c|c|c|c|c|}
\hline & Social & Legal & Economic & Environments & Political & Technological & $\begin{array}{l}\text { Priority } \\
\text { Vector }\end{array}$ \\
\hline Social & 1 & $1 / 3$ & 2 & 3 & 6 & 8 & 0.282 \\
\hline Legal & 3 & 1 & 3 & 6 & 2 & 2 & 0.344 \\
\hline Economical & $1 / 2$ & $1 / 3$ & 1 & 4 & 3 & 3 & 0.170 \\
\hline Environmental & $1 / 3$ & $1 / 5$ & $1 / 3$ & 1 & $1 / 2$ & $1 / 2$ & 0.048 \\
\hline Political & $1 / 6$ & $1 / 5$ & $1 / 3$ & $1 / 2$ & 1 & $1 / 3$ & 0.040 \\
\hline Technological & $1 / 8$ & $1 / 2$ & $1 / 3$ & 2 & & 1 & 0.116 \\
\hline
\end{tabular}

Table 11. Priority matrix for project selection

\begin{tabular}{lccccccc}
\hline & $\begin{array}{c}\text { Social } \\
(0.282)\end{array}$ & $\begin{array}{c}\text { Legal } \\
(0.344)\end{array}$ & $\begin{array}{c}\text { Economical } \\
(0.170)\end{array}$ & $\begin{array}{c}\text { Environmental } \\
(0.048)\end{array}$ & $\begin{array}{c}\text { Political } \\
(0.040)\end{array}$ & $\begin{array}{c}\text { Technological } \\
(0.116)\end{array}$ & $\begin{array}{c}\text { Overall } \\
\text { priority } \\
\text { vector }\end{array}$ \\
\hline $\mathrm{A}$ & 0.106 & 0.476 & 0.147 & 0.085 & 0.144 & 0.298 & 0.2627 \\
$\mathrm{~B}$ & 0.150 & 0.092 & 0.225 & 0.282 & 0.537 & 0.071 & 0.1554 \\
$\mathrm{C}$ & 0.271 & 0.158 & 0.467 & 0.534 & 0.173 & 0.431 & 0.2927 \\
$\mathrm{D}$ & 0.377 & 0.230 & 0.084 & 0.057 & 0.084 & 0.164 & 0.2248 \\
$\mathrm{E}$ & 0.096 & 0.044 & 0.076 & 0.041 & 0.062 & 0.036 & 0.0638 \\
\hline
\end{tabular}

The expect choice software can do the rest of the calculations automatically, or manually combined the criterion priority and the priority of each decision alternative relative to each criterion in order to develop an overall priority ranking of the decision alternative which is termed the priority matrix (Table 11).

The calculation for finding the overall priority of project are given below for illustrative purposes:

Overall priority of Project $\mathrm{A}=0.282(0.106)+0.344(0.476)+0.17(0.147)+0.048(0.085)+0.04(0.144)$ $+0.116(0.298)=\underline{0.2627}$

Overall priority of Project $B \quad=0.282(0.15)+0.344(0.092)+0.17(0.225)+0.048(0.282)+0.04(0.537)$ $+0.116(0.071)=\underline{0.1554}$

Overall priority of Project $C \quad=0.282(0.271)+0.344(0.158)+0.17(0.467)+0.048(0.534)+0.04(0.173)$ $+0.116(0.431)=\underline{0.2927}$

Overall priority of Project $\mathrm{D} \quad=0.282(0.377)+0.344(0.23)+0.17(0.084)+0.048(0.057)+0.04(0.084)$ $+0.116(0.164)=\underline{0.2248}$

Overall priority of Project $\mathrm{E} \quad=0.282(0.096)+0.344(0.044)+0.17(0.076)+0.048(0.041)+0.04(0.062)$ $+0.116(0.036)=\underline{0.0638}$

For selection, the projects are now arranged in overall priority in descending order of magnitude: $\mathrm{C}, \mathrm{A}, \mathrm{D}$, $\mathrm{B}$ and $\mathrm{E}$, showing $\mathrm{C}$ as the candidate road to be given priority attention for implementation. 


\subsection{CONCLUSIONS}

Selection of projects for implementation involves complex and daunting efforts to make scientifically sound decisions. In this paper, the AHP as a decision making process has been used with integrated factor base (IFB) taking into consideration, Social, Legal, Environments, Economic, Political and Technological (SLEEPT) factors that influence the selection of roads for implementation. By applying AHP, candidate projects have been prioritized in descending-order of the most viable project to be selected for implementation.

\section{REFERENCES}

Eugene, R. \& Dey, P.K. (2005). "The role of environmental factors in industrial site selection activities: A case of limestone quarry expansion in Barbados", Impact Assessment and Project Appraisal 23 (2).

Ghasemzadeh, F. \& Archer, N. P. (2000). "Project portfolio selection through decision support", Decision Support Systems 29, 73-88, 2000.

Haas, R. \& Meixner, O. (2005). An Illustrated Guide to Analytic Hierarchy Process. Vienna: University of Natural Resources and Applied Life Sciences.

Kendrick, J. D., \& Saaty, D. (2007). Use Analytic Hierarchy Process for Project Selection, Six Sigma Forum Magazine, Vol. 6, No. 8, pp. 22-29.

Lockett, G. \& Stratford, M. (1987). "Ranking of research projects, experiments with two methods". Omega 15, 395-400.

Mantel, S. M., Meredith, J. R., Shafer, S. M., \& Sutton, M. M. (2011). Project Management in Practice, (Fourth Edition), John Wiley \& Sons, Inc., Hoboken, NJ

Mehrez, A, \& Sinuany-Stern, .Z (1983). "An interactive approach to project selection", Journal of Operational Research Society 34, 621-626, 1983.

Odoki, J., Ahmed, B. F. A., Taylor, G., \& Okello, S, O. (2008). Towards the Mainstreaming of an Approach to Include Social Benefits within Road Appraisal: A Case Study from Uganda. The World Bank Groups, Transportation Paper, TP-17, Washington. DC.

Saaty, T.L. (1990). How to make a decision: the analytic hierarchy process. European Journal of Operational Research, North-Holland pg.48:9.

Saaty, T.L. (1985). Decision making for leaders. Belmont, California: Life Time Leaning Publications.

Saaty, T.L. (1980). The analytic hierarchy process. New York: McGraw- Hill, 1980.

Skibniewski, M.J., \& Chao, L. (1992). Evaluation of advanced construction technology with AHP method. Journal of Construction Engineering and Management, ASCE ,118(3):577 \pm 93 .

The World Bank (2008). Poverty data A supplement to World Development Indicators 2008, The world Development Data Group, Washington, D.C. 